\title{
Inheritors of the Yellow River: the relationship of heritage making practices to cultural self-confidence in China
}

\author{
Wanlin Zhang ${ }^{1}$ (D) $\cdot$ Stuart Walker ${ }^{1} \cdot$ Martyn Evans $^{2} \cdot$ Julia Bennett $^{3}$
}

Received: 2 February 2021 / Accepted: 8 April 2021 / Published online: 28 April 2021

(c) The Author(s). 2021

\begin{abstract}
Through active involvement in UNESCO's ICH (Intangible Cultural Heritage) programme, China has developed its own framework to support traditional making practices. To examine the 'characteristics' of heritage crafts preservation in China, we undertook empirical research in the Yellow River basin. Our research involved in-depth observations and key informant interviews with a range of highly accomplished craftspeople who have inherited their particular expertise from their family and have been officially designated ICH Inheritors. Through our qualitative research with inheritors, a businessperson and a government official, we identified various support mechanisms employed by the Chinese government that aim to protect traditional culture while also recognising outstanding individuals. We also found that $\mathrm{ICH}$ Inheritors play an important role in raising cultural awareness and enhancing cultural confidence through their creative activities and making practices, craft businesses and transfer of expertise. Based on the findings, potential areas where designers may collaborate with inheritors were identified.
\end{abstract}

Wanlin Zhang

w.zhang12@lancaster.ac.uk

1 ImaginationLancaster Design Research Centre, Lancaster University, Lancaster LA1 4YW, UK

2 Manchester School of Art, Manchester Metropolitan University, Manchester, UK

3 Crafts Council, London, UK 
Keywords Heritage making practices $\cdot$ Inheritor $\cdot$ Cultural self-confidence $\cdot$ Yellow River · Intangible cultural heritage - Design and cultural heritage

\section{Introduction}

This research was conducted by Lancaster and Manchester Metropolitan Universities in the UK as part of a collaborative three-year project - Located Making: Unlocking the Potential of Cultural Heritage by Design - funded by the UK Arts and Humanities Research Council (AHRC) Newton Fund. The research examines how design can increase the visibility and perceived value of heritage-based making practices in ways that accord with sustainability, decent jobs, economic growth and community (see Gateway to Research 2020). This project was conducted in collaboration with the Beijing Institute of Fashion Technology and Ningxia University and further develops Design Ecologies, a three-year knowledge exchange project involving the Chinese Academy of Social Sciences in Beijing.

As stated by the United Nations Educational, Scientific, and Cultural Organisation (UNESCO, 2001), 'cultural diversity is as necessary for humankind as biodiversity is for nature'. However, similar to other countries, globalisation and modernisation have negatively influenced the continuity of knowledge, traditions and practices within local communities in China (Kuah and Liu 2016, 1). Since the early 2000s, an Intangible Cultural Heritage (ICH) fever has swept across Chinese society (Maags 2018, 122). In recent years, as policy makers frequently referred to the construction of China's cultural self-confidence and cultural revitalisation where ICH protection has been given a high priority at the political level, contributing to the country's social cohesion and economic advancement (Yang 2018).

In China, the Yellow River is regarded as the 'Mother River' and the regions through which it runs have a long history of human activity (Xinhua Net 2019). One of these areas is Henan province, considered to be the cradle of Chinese civilisation and the birthplace of Chinese culture (China Daily 2010). This province has deep cultural roots and a very rich cultural heritage. Two of its historic sites have been included in UNESCO's World Heritage List, and there are 1372 entries, under 10 categories, in China's national list of the Representative Intangible Cultural Heritage (UNESCO, 2020a; ICH China 2020a). This paper presents findings from field research conducted in the Yellow River basin in Henan province that investigates this region's heritage making practices. Here, the term heritage making practices is used to refer specifically to local, long-established, traditional making practices that are regarded as part of the ICH of the region and country.

We begin by introducing the research context to familiarise the reader with four interrelated concepts in this study, namely China's cultural self-confidence agenda, the UNESCO ICH Programme, China's ICH Programme and its ICH Inheritors Programme. This is followed by a description of the methods employed and a presentation of the qualitative investigations. The findings reveal inheritors' motivations, the nature of their craft activities and making practices, and their craft business. Finally, the paper discusses ICH protection in China and its particular 
Chinese characteristics and makes recommendations for craft-design collaborations in this region.

\section{Research context}

Ancient China was home to one of the four early civilisations in human history. Its Confucianism-oriented culture dominated Chinese feudal society for more than 2000 years and deeply influenced East Asian communities (Wu 2014, 52). By the eighteenth century, China's cultural influence had been extended as international trade increased and Chinese luxury goods (particularly silk, porcelain and tea) were exported to the West. However, this came to an end with the outbreak of the First Opium War in 1840. Constant wars with 'western ideological invasion' put China in a deep cultural predicament (Zhang 2017). Chinese cultural confidence has fluctuated with the nation's development (Zhou 2012). Even though some attempts had been made for cultural reconstructions from the mid-nineteenth century to the mid-twentieth century, such as the New Culture Movement (1919) and the Cultural Revolution (1966-76), one common problem of these attempts was the self-denial of the traditional Chinese culture (Zhang 2017). In 2004, China signed up to the UNESCO Convention for the Safeguarding of ICH; 1 year later, the State Council announced every second Saturday of June as China's Cultural Heritage Day, and the Intangible Cultural Heritage Law was later passed in 2011(Gao, Zhang and Long 2017). Entering the twenty-first century, ICH preservation has been put on the new historic agenda of the nation, and therefore Chinese society is experiencing a transition from cultural self-denial to cultural self-awareness (Zhang 2017).

Intangible cultural heritage is defined by UNESCO as 'the practices, representations, expressions, knowledge, skills - as well as the instruments, objects, artefacts and cultural spaces associated therewith - that communities, groups and, in some cases, individuals recognise as part of their cultural heritage' (UNESCO 2018, 5). Traditional making practices are generally regarded as the 'most important tangible manifestations of ICH', and it recognises that more effort needs to be given to the continuity of skills and knowledge embedded in craftsmanship, rather than focusing on craft objects themselves (UNESCO, 2020b). Furthermore, as these kinds of making practices are closely tied to place and community (Walker et al., 2019a), in the design field, a bottom-up perspective is often taken in related conservation activities. Such design practices or projects involve:

- transmission of craft knowledge (Härkönen, Huhmarniemi, and Jokela 2018; Wood, Rust and Horne 2009);

- continuity of tradition and human values (Twigger Holroyd et al. 2017; Niedderer Townsend 2014);

- relationships between craft and sustainability (Zhan and Walker 2018; Väänänen Pöllänen 2020);

- cultural self-empowerment and social transformation through craft practices (Mamidipudi 2018; Vencatachellum 2019); and

- new opportunities facilitated by craft-design collaborations (Tung 2012; Chudasri, Walker and Evans 2020). 
In China, the ICH Department of the Ministry of Culture and Tourism is responsible for ICH safeguarding activities (MCT 2019a). A mechanism characterised as 'central initiative and local participation' is employed to create ICH and ICH Inheritors lists at the national, provincial, municipal and county levels (Kuah and Liu 2016). Inheritors are 'carriers' of ICH and have had this expertise passed down through their family and are often in a long line of craft makers who bear the responsibility for the inheritance and protection of national $\mathrm{ICH}$ practices through recognised representativeness, authority and influence ( $\mathrm{Su}$ et al. 2020). The ICH Inheritor programme is a national-level initiative which 'aims at protecting traditional culture while also recognizing outstanding individuals in order to encourage more people to become involved in promoting and developing China's intangible cultural heritage' (Beijing Tourism 2018). To apply for the ICH Inheritor programme, craftspeople submit an application to their local ICH department where their application is assessed through a strict screening process by an evaluation committee including academics and government representatives (MCT 2019b). If the application is approved, an annual stipend is provided by the government for artisans to disseminate aspects of their ICH to the public and to participate in related training events (Maags 2019). For example, a nationally-recognised inheritor receives an annual allowance of 20,000 yuan (about £2300). To date, according to five national ICH Inheritor Lists (2007, 2008, 2009, 2012, 2018), a total of 896 artisans have been designated as ICH inheritors (ICH China 2020b).

\section{Methods}

To better understand craft practices in China's ICH programme and better understand the role of inheritors in the sustainment of traditional heritage crafts, field studies in the Yellow River basin in Henan province were conducted in AugustSeptember 2019. A constructivist approach was adopted (Flick 2014, 76), whereby the local situation, and the priorities and values of craftspeople were interpreted from qualitative data collected during twelve in-depth interviews with a representative sample of highly accomplished ICH Inheritors and key stakeholders. These interviews were supplemented with direct observation of their making practices in their places of work.

The specific interviewees and the making practices selected from this region was purposive. According to official ICH lists of this region at national and provincial levels, local heritage-based making practices can be loosely categorised as musical instruments, paper artefacts, metal-ware, carved artefacts, porcelain and embroidery crafts (ICH China, 2020a; CTD Henan 2020). In our previous linked research projects, we had conducted research in the city of Jingdezhen, which is known as the Porcelain Capital of China, and Suzhou where its Su embroidery regarded as one of the four famous Chinese embroideries (see Walker et al., 2019a; Zhan and Walker 2018). Therefore, in this region, more attention was given to the other four categories, namely: musical instruments, paper artefacts, metalware, and carved artefacts. To identify participants, the researchers firstly visited Henan ICH Research Institute to acquire the contact information of makers within 
these four fields. The makers were contacted via phone or WeChat (a Chinese mobile application, equivalent to WhatsApp). Two of them were willing to be interviewed. With their help, we were introduced to other inheritors, and from this ensured an evolving snowball sampling procedure. This method was used as the primary means for identifying suitable participants, enriching sampling clusters, and accessing new participants and social groups (Noy 2008).

In total twelve participant interviews were conducted in this region (denoted as A1-A12). Ten interviewees were ICH Inheritors, and 2 were craft-related people, specifically a businessman and a government official (see Table 1). A1 is a province-level inheritor who had made and sold paper kites for more than 40 years. Because his eyesight has been falling since 2006, he was no longer able make kites. However, his daughter A2 has taken up the craft but she focuses mainly on teaching the heritage and skills of kite making. Both A3 and A4 are city-level inheritors. A3 makes the traditional Guqin musical instrument (a type of Chinese zither) and also teaches the craft at a local university. A4 is a master leather

Table 1 Interviewees and their roles; Yellow River Region, Henan Province

\begin{tabular}{|c|c|c|c|c|c|c|}
\hline ID & Sex & Age & Interviewee & $\begin{array}{l}\text { Working } \\
\text { Years }\end{array}$ & Date & Location \\
\hline A1 & M & 71 & $\begin{array}{l}5 \text { th generation of } \\
\text { kite maker, }\end{array}$ & $40+$ & $\begin{array}{l}30 / \\
08 / \\
2019 \\
23 / \\
09 / \\
2019\end{array}$ & $\begin{array}{l}\text { Kaifeng } \\
\text { city }\end{array}$ \\
\hline A2 & $\mathrm{F}$ & 44 & $\begin{array}{l}\text { 6th generation of } \\
\text { kite maker, teacher }\end{array}$ & $20+$ & $\begin{array}{l}30 / \\
08 / \\
2019\end{array}$ & $\begin{array}{l}\text { Kaifeng } \\
\text { city }\end{array}$ \\
\hline A3 & M & 46 & $\begin{array}{l}\text { 4th generation of } \\
\text { Guqin (Chinese } \\
\text { Zither) maker, }\end{array}$ & $20+$ & $\begin{array}{l}24 / \\
09 / \\
2019\end{array}$ & $\begin{array}{l}\text { Zhengzhou } \\
\text { city }\end{array}$ \\
\hline
\end{tabular}

A4 M $50 \quad$ 4th generation of leatherware maker

24/ Zhengzhou 09/ city 2019

A5 $\quad$ M $48 \quad \begin{aligned} & \text { Ruan (Chinese } \\ & \text { plucked string } \\ & \text { instrument) maker }\end{aligned}$

31/ Lankao 08/ county 2019 24/ 09/ 2019

\begin{tabular}{|c|c|c|c|c|c|c|}
\hline A6 & M & $40+$ & $\begin{array}{l}\text { Instrument company } \\
\text { owner }\end{array}$ & 22 & $\begin{array}{l}24 / \\
09 / \\
2019\end{array}$ & $\begin{array}{l}\text { Lankao } \\
\text { county }\end{array}$ \\
\hline A7 & $\mathrm{F}$ & 53 & $\begin{array}{l}5 \text { th generation of } \\
\text { river clay carver }\end{array}$ & $30+$ & $\begin{array}{l}25 / \\
09 / \\
2019\end{array}$ & $\begin{array}{l}\text { Zhengzhou } \\
\text { city }\end{array}$ \\
\hline A8 & M & 54 & $\begin{array}{l}\text { 18th generation of } \\
\text { drum maker }\end{array}$ & $40+$ & $\begin{array}{l}29 / \\
08 / \\
2019 \\
27 /\end{array}$ & $\begin{array}{l}\text { Luoyang } \\
\text { city }\end{array}$ \\
\hline
\end{tabular}


Table 1 (Continued)

\begin{tabular}{llll}
\hline ID Sex Age Interviewee & $\begin{array}{l}\text { Working Date Location } \\
\text { Years }\end{array}$ \\
\hline
\end{tabular}

\begin{tabular}{|c|c|c|c|c|c|c|}
\hline & & & & & $\begin{array}{l}09 / \\
2019\end{array}$ & \\
\hline A9 & $\mathrm{M}$ & 53 & $\begin{array}{l}5 \text { th generation of } \\
\text { New Year prints } \\
\text { woodblock maker, } \\
\text { historic old brand } \\
\text { owner }\end{array}$ & 27 & $\begin{array}{l}29 / \\
08 / \\
2019\end{array}$ & $\begin{array}{l}\text { Kaifeng } \\
\text { city }\end{array}$ \\
\hline A10 & M & 48 & $\begin{array}{l}\text { 7th generation of } \\
\text { lantern maker, } \\
\text { lantern museum } \\
\text { curator }\end{array}$ & $20+$ & $\begin{array}{l}31 / \\
08 / \\
2019\end{array}$ & $\begin{array}{l}\text { Kaifeng } \\
\text { city }\end{array}$ \\
\hline A11 & $\mathrm{M}$ & 34 & $\begin{array}{l}\text { 5th generation of } \\
\text { ironware maker }\end{array}$ & 14 & $\begin{array}{l}08 / \\
09 / \\
2019\end{array}$ & $\begin{array}{l}\text { Zhongmu } \\
\text { county }\end{array}$ \\
\hline A12 & $\mathrm{F}$ & $30+$ & Government official & $5+$ & $\begin{array}{l}04 / \\
09 / \\
2019\end{array}$ & $\begin{array}{l}\text { Luoyang } \\
\text { city }\end{array}$ \\
\hline
\end{tabular}

craftsman, he creates the prototypical designs, trains apprentices and runs two leatherwear shops. A5 is a province-level inheritor of Ruan making (a horizontal stringed instrument - another kind of Chinese zither), and he works at A6's instrument company. A7, A8 and A9 are also province-level inheritors. A7 is a sculptor who uses clay-like mud from the banks of the Yellow River; the themes in her work are based mainly on the Yellow River culture. A8 is the 18th generation in his family making traditional ceremonial drums. A9 creates historic 'old brand' woodblock New Year prints, which are printed from intricately carved wooden patterns. A10 is a nation-level inheritor of traditional paper lantern making for large festivals such as Chinese New Year celebrations; he also initiated and runs a lantern museum at his ancestral house. As a county-level inheritor, A11 works with his father to make ironware for household and agricultural use. A12 is a government official who works in local culture bureau.

Each interview lasted approximately $60-90 \mathrm{~min}$. Adopting a semi-structured interview style can allow a more open approach and is a suitable way to establish a reliable evidence base to draw out generalizable findings (Burns 2000). To understand the values, priorities and motivations of inheritors and their craft work, interviews included questions about the interviewee's background, why they started working in traditional crafts, details of their practices, their perceived value of their work, how they promoted their work, and their activities in the ICH programme. Interviews were audio-recorded, and one of the authors (a native Mandarin speaker) served as interpreter and translator. During or directly after the interviews, observations were recorded of the working environment, making processes and craft expertise. The researchers also photographed the workshops, tools and artefacts, and employed note-taking during the interviews. For data analysis, an open coding method was used (Flick 2014, 404-6). Manual coding on sticky notes was employed to condense the mass of data and through this process enabled the 
researchers to develop an in-depth understanding (Neuman 2007) and thus decipher and interpret patterns leading to the identification of themes (Böhm 2004). Through thematic analysis (Braun and Clarke 2012), iterative clustering and refinement of related codes enabled a series of cognate concepts to be identified in relation to the focus of the research.

\section{Findings}

The thematic data analysis revealed four key themes: (1) Motivations of Inheritors, (2) Making Practices, (3) Craft Business, and (4) Craft Activities in China's ICH Programme.

\section{Motivations of inheritors}

All ten interviewed craft-makers (see Table 1) learned their skills from family members with some showing great interest in these heritage practices from an early age. Some decades ago, being a craft-maker was a good way of making a living. Five interviewees identified this as their initial motivation for starting a career in craft (including A1, A5, A8, A9, A11). However, as handmade objects have now been largely replaced by mass-produced alternatives, there is a need to understand why these makers still devote themselves to their craft. Here, analysis of the interviews identified two important motivations: (a) a sense of responsibility to continue the tradition, and (b) self-fulfilment.

A sense of responsibility to continue the tradition When inheritors were asked about their motivations for continuing these practices, the concept of responsibility was frequently mentioned - a strong sense of responsibility to continue the tradition. This was especially the case when they had been designated as an ICH Inheritor at the national, provincial and/or municipal level. A10 described a significant change when their family's ceremonial lantern making business was included in the list of China's national ICH:

Fig. 1 Traditional lanterns are exhibited in a museum which was refurbished from inheritor Juntao Zhang's ancestral house, Kaifeng, China (authors' photo, 2019)

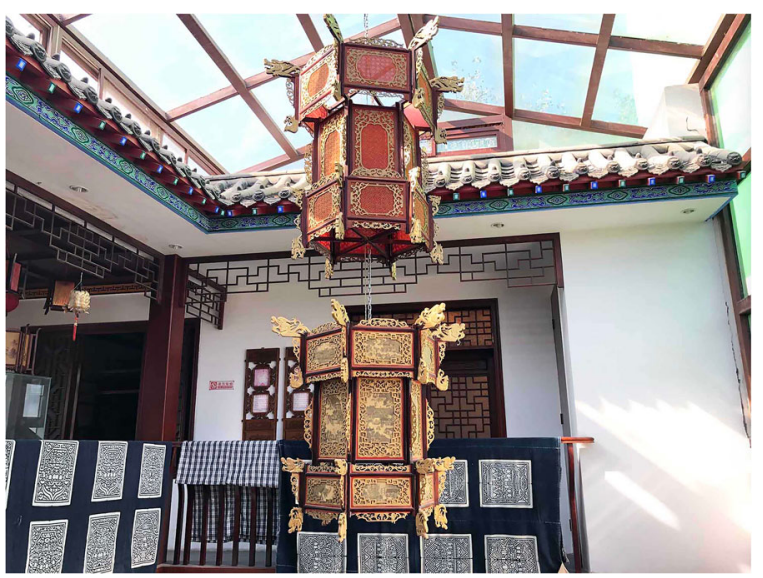


Since the time of my grandfather, we produced lanterns to make a living. Our craftsmanship was inscribed in the national list of ICH in 2008, and since then there has been a shift in focus from making profits to spreading knowledge, understanding and skills. Because this making practice represents the nation, we shoulder a responsibility to enable more people to know about it ... To spread the skills, we gave more than fifty free courses to students at primary schools, senior schools, high schools and universities last year. We also refurbished our ancestral house as a lantern museum (see Figure 1). It has been open to the public since June 2011 and about 20,000 people visit our museum each year (interview with A10, 2019).

In some cases, such responsibility can be explained as a commitment to the family and community. For example, A8 told us his family began making ceremonial drums in the Ming dynasty (1368-1644), and he is the 18th generation in this family practicing the craft. He mentioned that his son did not really want to do this job as it is difficult and dirty. His son became a truck driver instead, but in his early thirties he took up the craft because 'he also felt a sense of responsibility to continue this family-based drum making craft tradition' (interview with A8, 2019).

Consequently, his son is now the 19th generation in his family to be a drum maker. Similarly, the 5th generation of New Year prints woodblock maker (A9) told us his responsibility 'is to inherit this making practice and also develop the historic old brand as a successful enterprise'. He said, 'I hope our enterprise will finally bring both economic and social benefits to the local community and local people' (interview with A8, 2019).

Personal fulfilment Craft makers repeatedly mentioned the sense of personal fulfilment they gained from their work. For example, A5 said he had 'a sense of achievement in making musical instruments that can produce beautiful music' (interview with A5, 2019). The Yellow River clay sculptor shared her ambition with us, 'to let more people know about this craft and art' (interview with A7, 2019). As more and more people today re-appreciate her culture-specific practice, she feels a great deal of personal fulfilment. Similarly, A8 mentioned a sense of personal fulfilment when his work was used in important ceremonial activities. This was especially the case when a $3 \mathrm{~m}$ diameter drum he had made was used for the celebration of the Hong Kong handover in 1997; he said he had 'a sense of honour' (interview with A8, 2019).

We found craft teaching activities are closely associated with personal selfactualisation. A2, A3 and A4 have been invited to teach in schools, colleges and universities. They share their knowledge with the students and teach them skills.

For me, as an inheritor of kite making, heritance means ensuring more people know about this practice, raising their interest in learning about it and teaching them the necessary skills. To do so, I developed this experiential course and designed kite kits ... I am happy to teach students, it is very fulfilling (interview with A2, 2019). 
These teaching activities are consistent with craft people's intrinsic values and goals, and so are associated with positive emotions, such are satisfaction and happiness as indicated by A4 who stated 'I am very satisfied. My students respect me. I love this work' (interview with A4, 2019).

\section{Making practices}

Purpose Most craftspeople we interviewed create their work for daily needs and practical use. Handmade objects such as river-clay inkstone; leatherware like rucksacks, bags and belts; ironware for household or agricultural use, such as knives, axes and sickles; musical instruments for performance and entertainment. Among these artefacts, in particular, the function of drums had changed over their long history. A8 stated originally they were invented to drive away wild beasts from the farms and villages. Later they were used to accompany the army while it marched, and were also used in the royal palace for entertainment. Today, these types of drums are predominately used in folk activities and ceremonies at regional and national levels.

In the case of New Year woodblock prints, the prints themselves are relatively inexpensive. However, the craft skill, in the form of woodblock carving, is highly

Fig. 2 The Guqin musical instrument (authors' photo, 2019)

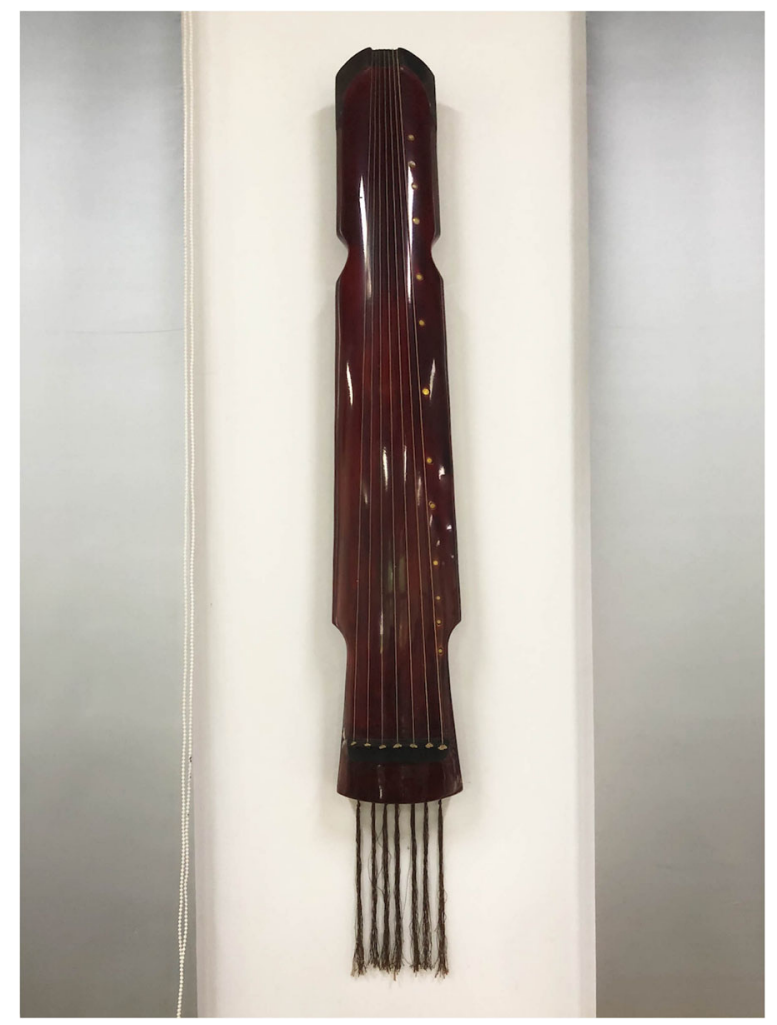


Fig. 3 Large wall relief sculpture made from Yellow River mud (authors' photo, 2019)

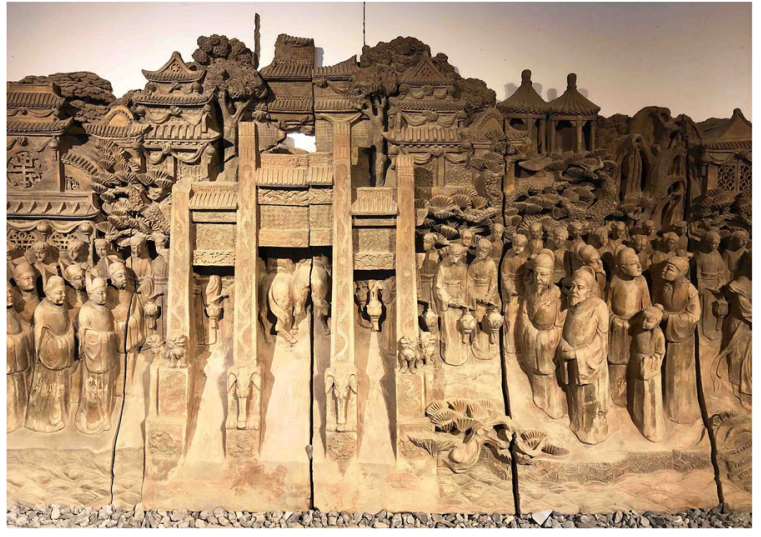

skilled, meticulous and time consuming. The resulting prints have an important symbolic meaning while also be decorative. At New Year, they are pasted onto the doors of houses to bid farewell to the past year and welcome in the New Year. The traditional stringed instrument known as the Guqin (Fig. 2) also has a symbolic significance, as it connects with the ancient Chinese philosophy of Yin and Yang. The curved top of the Guqin represents the sky, which is Yang, and the flat base represents the earth, which is Yin. Yin and Yang exist as inseparable and contradictory opposite, just like sky and earth, but at the same time, these two contrary poles are complementary, which represents balance and harmony (Cartwright 2018). It is notable that, in the case of woodblock prints and the Guqin, symbolism is at the heart of the artefact; this is more significant than their decorative qualities or even their utilitarian purpose.

Materials Typically, craft objects are handmade from locally available materials. A7 collects clay-like mud from the banks of the Yellow River (Fig. 3). A9 uses traditional ways of transforming plants into pigments noting that 'we do them as we were taught' (interview with A9, 2019). However, some local materials are no longer used; to improve the product, they have been replaced by alternatives. Leatherware maker A4 uses leather from Japan, Italy and America because these imported leathers are of higher quality than local leathers (Fig. 4). Similarly, synthetic glue has largely replaced traditional animal glue (traditionally made from boiled off-cuts from pigs) in the making of the Chinese stringed instrument known as the Ruan because modern synthetic glues have stronger adhesive properties. However, drum maker A8 was forced to change from using local leathers to leather imported from the south of China. This was because changes in local farming practices in the 1990s meant that the local water buffalo are killed for meat when they are still young animals. At this young age, the leather is not yet strong or thick enough for use as drum skins.

It is critical to choose suitable materials with good qualities for making, therefore, craft-makers are normally materials experts and have a deep understanding of their properties. This is especially evident in the cases of stringed instruments. Craft-makers apply strict criteria in choosing woods, considering their durability, 
Fig. 4 Leather hand bag with intricate carving (authors' photo, 2019)

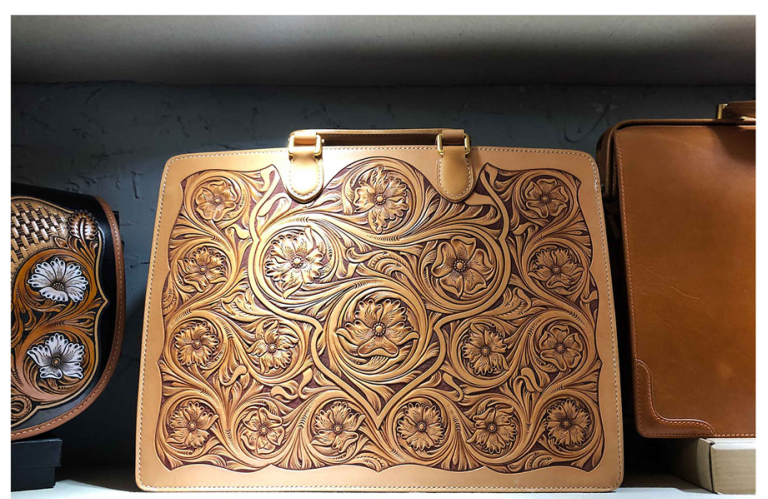

strength and acoustic properties. Following selection, there is a long period dedicated to wood treatment. For example, in the case of A5, high quality Tung wood (a deciduous tree often grown for its oil) is an important material in the making of the Ruan, however, before it can be used in instrument making it has to be dried over a long period.

We firstly soak Tung woods in liquor for almost one month, and then leave them to be air-dried for a while. A purpose-built dryer is later used for a second round of drying. After these steps, wood planks are air dried for about three years. By using this slow drying process, deformation or cracks in the future can be largely avoided (interview with A5, 2019).

Production The craft practices we studied usually had a small-scale of production (less than 10 people). Four of our interviewees were sole makers, (A1, A2, A3 and A10). A1 and A2 chooses specific customised orders for producing kites, such as orders for the old-style kites that appear in Chinese historical dramas or movies, and also miniature kites that are framed by collectors as art pieces. In the case of A7, A8 and A11, a family-based production model is adopted. A11 works with his father to make iron farm tools and knives in busy periods. His mother and his wife

Fig. 5 Ruan musical instruments co-made by several craftspeople (authors' photo, 2019)

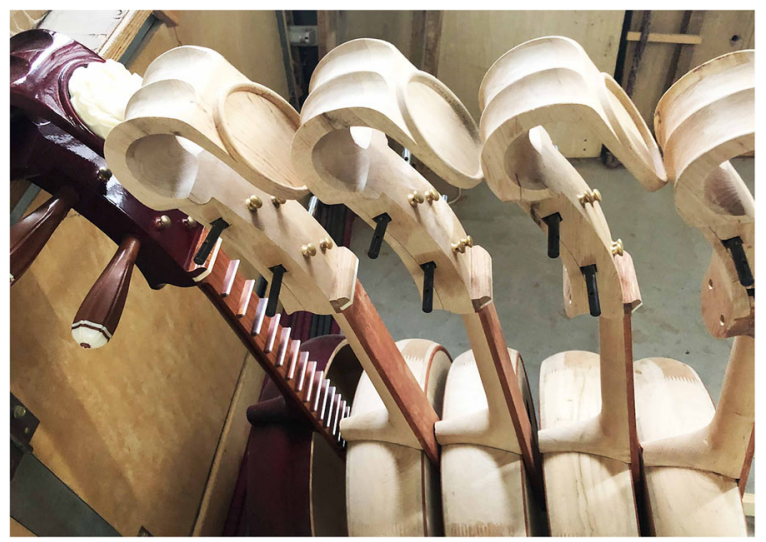


are in charge of order processing and selling. Similar to this small-scale craft business based on family, A4 and his students work together to produce enough stock for his two shops. He develops the new designs, which he prototypes himself. After this, he teaches his students, then these students make leather products at their homes or their own studios.

In a larger craft business, we also found that collaborative approaches are used to support production. In A6's musical instrument company (where A5 works), there are about sixty employees, forty of whom are craftspeople. The making process has been divided into many steps, with division of labour. The early steps require lower levels of skill and less precision; the majority of craftspeople can make these components. A highly skilled craftsperson, like A5, does the more skilled, intricate tasks and puts the instrument together (Fig. 5). In A9's business of woodblock making for Chinese New Year prints, about 15 craft-makers work in his enterprise. Apart from these permanent employees, he also collaborates with other small local studios and sole makers, in order to fulfil his orders during busy periods.

Notably, local craftspeople pay attention to environmental considerations in their production. Even in the case of ironware, where there is a need for firing and casting and is therefore energy intensive, consideration is given to the type of energy source. To reduce air pollution caused by traditional coal burning, blacksmiths (A11 and his father) now strive to improve their techniques and use the cleaner energy source of natural gas.

\section{Craft business}

Word-of-mouth marketing and promotion The marketing and promotion of craft products is frequently via word-of-mouth among collectors and other buyers. For example, A11's father started off by selling his work at the local market. As he had gained a reputation for making quality ironware, he no longer needed to worry so much about finding customers, they came to him. For other sole makers, they do not advertise because their production is limited. One interviewee said, 'If we had too many customers it could be a problem, because we cannot make so many bags' (interview with A4, 2019). Similarly, A3 makes less than 10 Guqin instruments in a year. He said, 'all the instruments [I made and sold] are luxury items and special, so I do not need to promote my work' (interview with A3, 2019). For sole makers and craft enterprises, social media also contributes, through 'virtual word-of-mouth' especially via the widely used social media application WeChat. Through its social-networking function known as Friends Circle, craftspeople post pictures or videos of their craft work, craft activities and making process. The lantern maker described the reputation established via Wechat moments as, "the most reliable and stable' (interview with A10, 2019). Additionally, social networking services, including Weibo (a microblogging application and website) and TikTok (a video-sharing application), are also widely used to enhance the reputation of makers and their artefacts. A9 highlighted, 'it is necessary to take advantage of the internet and social media today, as they are closely connected with our life' 
(interview with A9, 2019). Government ICH advisers also supplement word-of mouth marketing through their networks and by providing access to initiatives to promote Inheritors' work. A2, A7 and A9 all noted the benefits of this support.

Selling and 'route-to-market' With marketing via word-of mouth and social media, those who wish to purchase can add craftspeople as 'friends' and contact them on WeChat; its mobile payment service also enables purchasers to transfer money. Many craftspeople use this to directly sell to their customers. However, most do not use specific e-commerce sites to sell their work. A8 used to sell his drums via Ali Baba (the largest Chinese e-commerce website), but this was not successful due to price competition. 'Other factories also make similar looking drums and sell online. But we make drums using very good materials. This is why ours are more expensive' (interview with A8, 2019). On these platforms, 'massproduced products with cheaper prices sell well. Customers tend to pay more attention to price than quality when they shop on these e-commerce sites' (interview with A5, 2019). In contrast to online selling, it is better to sell traditional, handmade artefacts through face-to-face interactions and maker reputation. In A4's shop, we observed that he always patiently introduces information to customers, such as the techniques of leather making and the details of his design concepts. This way, buyers can appreciate the skill, time and quality of workmanship that has gone into the product and hence its value.

\section{Craft activities in China's ICH Programme}

Many inheritors believe their practices contribute to a sense of cultural selfconfidence. 'Our president Xi and other policymakers refer to 'cultural confidence', so I am following this trend' (interview with A7, 2019). The concept of 'cultural self-confidence' was described by politicians as 'a state of mind that is based on the full affirmation of the country and the culture of the country, resulting in a sense of cultural honour and firm faith' (Yang 2018).

To enhance cultural self-confidence through ICH activities, China has implemented two strategies - 'creative transformation' and 'innovative development' -

Fig. 6 Door God Woodblock prints. (authors' photo, 2019)

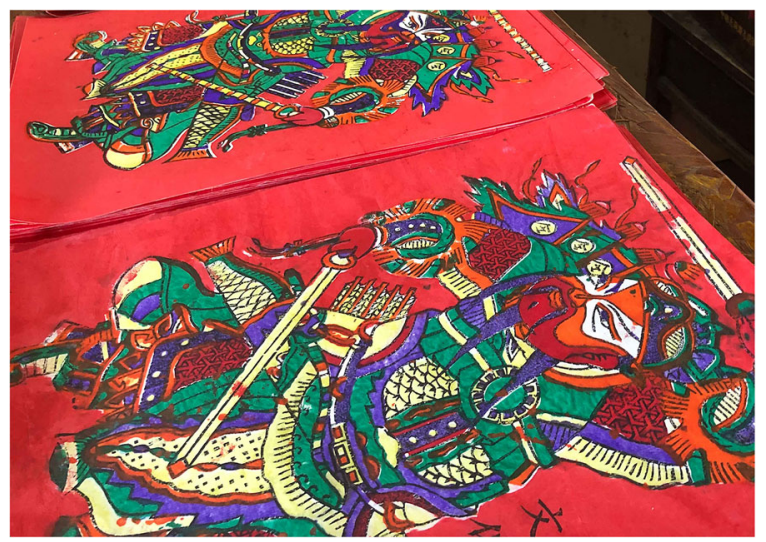


to facilitate collaborations and generate new opportunities (China Daily 2017). In the case of woodblock making for New Year prints, A9 collaborates with research institutions and local universities. A new technique has been developed to woodblock print on red papers (Fig. 6). Compared with traditional New Year prints, which have a white background, these new types of red prints are an example of 'innovation within traditional crafts, enabling them to remain both relevant and vibrant' (Walker and Evans 2018, 273). They symbolise luck, joy and happiness in Chinese culture and, consequently, they have become very popular; even more popular than the traditional prints. In addition, an animation about traditional wood-carving skills has been collaboratively developed, which is played in his shop for customers. Another inheritor (A10) is also exploring collaborative opportunities with research institutions or corporations.

I have collected more than 60,000 examples of old, wood-carved craftwork that have traditional patterns on them and are of great cultural value. I would like to build a digital library of these traditional patterns, which could provide a resource for creative developments and transformations in the future (interview with A10, 2019).

During our interview with a government official from the local culture bureau (A12), she told us that her daily work is to identify, record, document and disseminate $\mathrm{ICH}$ projects. For heritage-based craft practices, their making processes, technique and details are video-recorded or photographed (interview with A12, 2019). Additionally, local cultural heritage is seen by the government as a resource to develop the local tourism industry, generating commerce and profits for the local economy (Maags, 2018, 124). In our visits to the Longmen Grottoes and Luoyang Museum in this region, we saw many souvenir shops selling porcelain, embroidery and other local crafts as well as books and other items. However, the government official pointed out some of the cheaper craft-like souvenirs do not accurately represent the cultural values of traditional crafts. She also told us that crafts differ from art objects - more consideration should be given to their functional use (interview with A12, 2019). This was also highlighted by A9 and A10, who said cultural and spiritual needs as well as functional needs are the key for craft designs.

Due in large part to their status as inheritors, the ten craftspeople we interviewed felt a strong responsibility to continue the craft and devote energy to cultural transmission. One example was the creation of a two-hour practical course, taught by inheritor A2. As a precursor to the practical part, a 15-min introductory session informed participants about the history of her family's kite-making, the various designs, and the exhibitions where their kites have been displayed. Students then use kite kits to engage in a simplified version of kite making. The kit designed by A2 comprises a black and white, printed, two-headed parrot kite pattern; two ribbons; three shaped bamboo sticks; a plastic needle; white glue; a kite handle with line'; a paint brush; and a set of gouache paints with six colors (Fig. 7). She has streamlined the processes and reduced the number of steps. The time-consuming element of hand-carving the 
Fig. 7 Kite kits used for teaching (authors' photo, 2019)

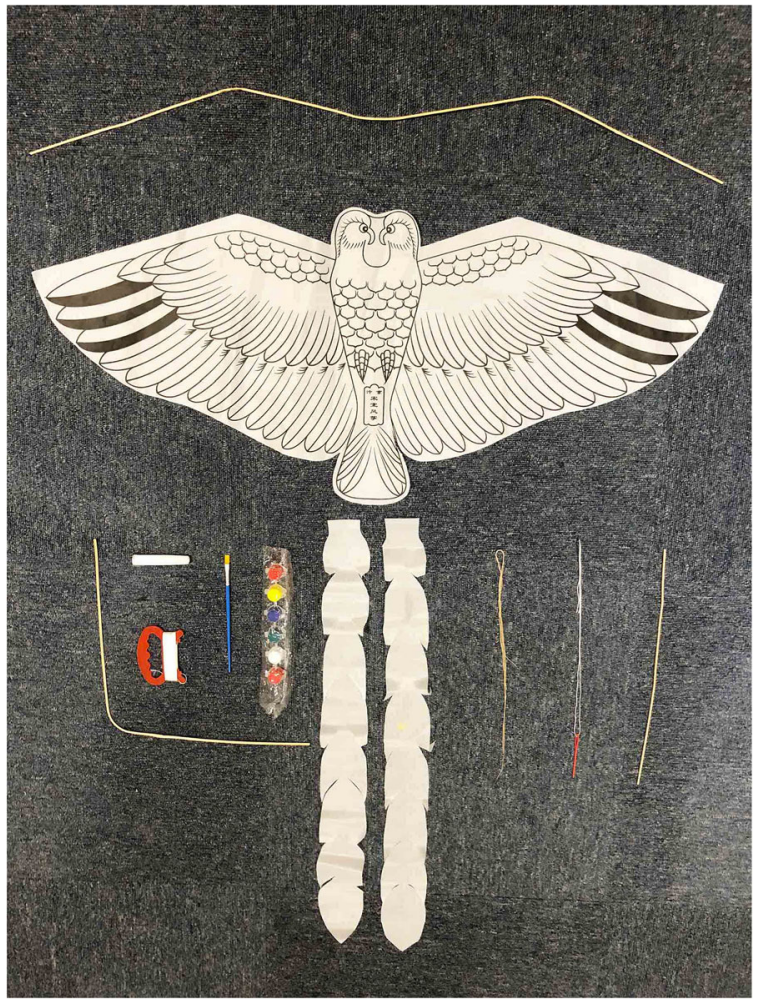

bamboo sticks into lightweight careful profiled rods has been replaced by mass-produced bamboo sticks of uniform profile. Silk and paper for traditional kites have been replaced by waterproof plastic sheet, which is more robust and prevents the kites being damaged when taken out in the rain. In last 2 years, she has taught about 15,000 students this simplified version of traditional kite making (Fig. 8). Similarly, other inheritors we interviewed also spend time teaching for non-commercial reasons. Specifically, in the cases of A3 and A7,

Fig. 8 Inheritor Song gave a kite making course at a primary school, Kaifeng, China. (Photo courtesy Changhong Song)

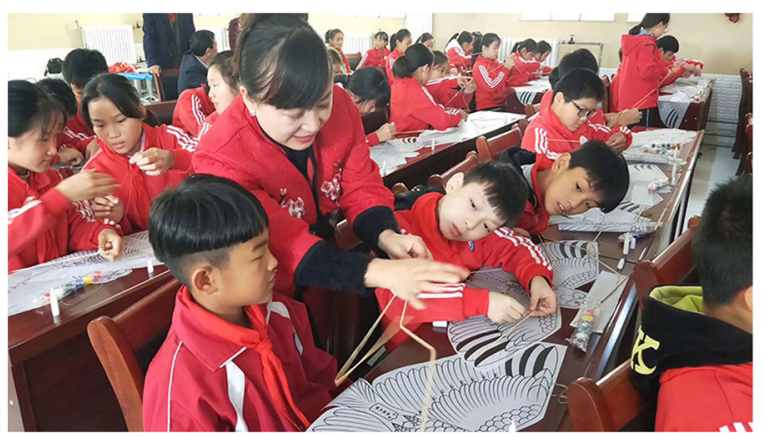


they teach craft skills to disabled students, in order to help them become selfemployed.

We also found that there are various support initiatives provided by the government within the ICH Programme. For example, government departments organise annual meetings that enable craft inheritors to attend talks and workshops, to meet with other craftspeople and to exhibit their work. A2 shared her experience of attending workshops sponsored by the China National Arts Fund. These are opportunities to learn about cultural heritage from researchers, and to meet other kite-makers and discuss techniques, pricing, customers and routes to market. The government also organises craft exhibitions in China and abroad, offering the craftspeople funded opportunities to travel and meet craftspeople from elsewhere. Through this government-funded programme, A7 has visited Malaysia, Korea, America and Australia to exhibit her river clay work. Both her and A9's craftworks are also used by their local government as gifts during their international visits. As a consequence, these craft activities have received a great deal of media attention. All of the inheritors we interviewed have had their craftwork and stories widely reported in newspapers, websites, TV programmes or on social media.

\section{Discussion}

\section{The potential for craft-design collaborations in the Chinese context}

Our research revealed a range of top-down mechanisms by the Chinese government aimed to safeguard heritage making practices. This contrasts with approaches elsewhere. For example, in the UK, the main focus of heritage and conservation activities is on tangible heritage in the form of buildings and artefacts. In terms of intangible cultural heritage, traditional making practices in the UK are supported mainly through smaller, bottom-up mechanisms, particularly non-governmental organisations such as the Heritage Crafts Association (Walker et al., 2019b) and the Crafts Council. Craft activity in the UK is 'situated within the parallel policy frameworks of culture, which focuses broadly on access and participation, and the creative industries, which is driven by the economic growth agenda' (Bennett 2019, 144). The latter approach emphasises craft as one of the constituent disciplines that make up the creative industries (Department for Culture, Media and Sport, 1998). To support and develop craft in the UK, the Crafts Council curates exceptional presentations of craft, champions craft education and helps makers and craft enterprises to flourish creatively and commercially. Its work is underpinned by advocacy and promotion of craft and it commissions research to demonstrate the nature and value of crafts to the UK economy. Whilst supported in part by public funding, a significant proportion of the Crafts Council's work is funded by trusts and foundations and individual donations. In contrast, in China, through enthusiastic participation in UNESCO's ICH programme, its top-down support mechanisms appear to help sustain the continuity of crafts for cultural rather than primarily 
commercial reasons. Hence, the value of craft is in its contribution to the nation's cultural, rather than economic, wealth. Craftspeople in China, like their counterparts in the UK, are, nevertheless, dependent for the majority of their livelihoods on sales of their work. This may have been a factor leading to the innovation in practice and diversification of role witnessed with A2, A3, A4 and A10 (see also Walker and Evans 2018).

Inheritors, as local cultural practitioners, are significant contributors to cultural identity and community belonging through their making practices and related activities. Our findings on personal motivations highlighted inheritors are predominately driven by a sense of responsibility to the craft and towards community and the self-fulfilment from the work. These motivations fall within the cluster of intrinsic values which relate to self-transcending values of benevolence (in relation to family and community), universalism (broader concerns for people and environment), and conservation (tradition and continuity) (Schwartz 2012). These kinds of values and priorities are very much in keeping with traditional cultural values and craft teaching activities and therefore contribute to building a sense of cultural selfconfidence. This contrasts starkly with external approval and rewards, such as the self-oriented, get-rich-quick motivations of some big companies today, in both the East and West, which reflect greed and have nothing to do with culture or cultural self-confidence.

Noticeably, a call for collaboration has been repeatedly mentioned by some inheritors in our study. In recent years, many designers have collaborated with craftspeople and are regarded as 'an indispensable intermediate' in order to re-examine and reassess the contemporary value and contribution of heritage-based making practices (Vencatachellum 2019, 32). Designers collaborate with craftspeople to develop new opportunities related to their local crafts often aspiring to develop innovation with tradition. However, some design interventions are criticised by researchers because local artisans' voices can be neglected. When this occurs, craftspeople become mere producers of products that have become severed from their original cultural context and cultural roots (Bissett-Johnson and Moorhead, 2019; Murray, 2012; Vencatachellum 2019, 32). To avoid this, the designer has to serve 'the role of a facilitator', assisting craftspeople in the preservation, development and marketing of their crafts (Sanders and Stappers 2008).

Our findings on craft business and craft activities revealed particular areas where the designer may collaborate with the inheritor in the development and sustainment of traditional heritage crafts. As inheritors shoulder a responsibility to pass their skills and knowledge onto others, there is potential for additional design in the field of heritage teaching. For example, in the case of A2, silk and paper in traditional kites have been replaced by waterproof plastic sheet, however, this can also contribute to the problems associated with environmental waste. By working with a designer who is well versed both in materials use and sustainability, the selection of alternative materials can result in choices that are both functional improvements and adhere to sustainable principle. This highlights the fact that both craft makers and designers have to be very careful when introducing changes and innovations if they are to uphold the values and priorities of cultural traditions. As interviewees A10 and 
A12 stated, when collaborating with designers, they are encouraged to satisfy contemporary needs while remaining true to tradition.

In addition, there is also the potential for design visualisation of making process, materials and skills in craft branding and marketing, as we witnessed in A4's shop. Another specific need was underlined by A9 - to design a digital museum of traditional patterns. There is potential for this idea to be explored further. Existing literature indicates specific digital technologies have contributed to $\mathrm{ICH}$ preservation. For example, the use of serious games (Dagnino, Pozzi and Tsalakanidou 2015), livestreaming (Lu et al. 2019), augmented and virtual reality (Huang, Xiang and Li 2019) have been explored in the transmission, documentation and education of $\mathrm{ICH}$.

\section{Conclusion}

This study in the Yellow River basin provides wider understanding of heritage making practices in the Chinese context and provides new, evidence-based arguments for the contribution of traditional heritage crafts towards enhanced cultural self-confidence. Impressively, the Chinese government provides various kinds of support at the individual, socio-cultural and economic levels. Specially, its recognition and financial support of craft making practices helps raise the profile of place-based culturally relevant practices, designs and products, and serves to sustain them by bringing them to the attention of the general public and creating interest in them among younger people. This top-down approach appears to contribute positively to the continuity of cultural significance and understanding of such programmes may well be useful in policy contexts in the seventeen countries that are not yet signatories to the UNESCO Convention on Intangible Cultural Heritage.

Our research also reveals the significant role of 'inheritors' in raising cultural awareness and enhancing cultural self-confidence. Based on detailed analysis of in-depth interviews and field-based observations, their contributions can be identified in four key areas: (a) the devotion to cultural transmission driven by intrinsic values, (b) the making practices in China's Intangible Cultural Heritage, (c) the craft objects emerged from making practices, which is part of China's Intangible Cultural Heritage, and (d) in those cultural activities, ceremonies, rituals and performances enabled by these craft products. These areas are of particular relevance to both policy and practice as well as advancing scholarly thought in the fields of $\mathrm{ICH}$, craft and design. For future design research, we identified potential areas where the designer may collaborate with the inheritor in the development and sustainment of traditional heritage crafts and they continue to evolve. These include the design opportunities for advancing innovation within traditional boundaries, heritage teaching and craft courses, the conveyance of tradition and culture in craft branding and marketing, and the use of specific technology in the transmission, documentation and education of ICH. 
Acknowledgements We would like to thank all interviewees for their time. We are also grateful for the contributions of our colleges at the Chinese Academy of Social Science (Beijing), Beijing Institute of Fashion Technology and Ningxia University in China for their support during this research.

Authors' contributions This paper is an output from a research project conducted by Professor Stuart Walker of Lancaster University, Professor Martyn Evans of Manchester Metropolitan University and colleagues at the Chinese Academy of Social Science, Beijing, China, and Ningxia University, China. The paper was jointly and collaboratively authored by Wanlin Zhang, Stuart Walker, and Martyn Evans with project input by Julia Bennett from the UK Crafts Council. All authors read and approved the final manuscript.

\section{Authors' information}

Wanlin Zhang is Researcher for Located Making project and a Ph.D. candidate at the ImaginationLancaster Design Research Centre, Lancaster University, UK under the supervision of Professor Stuart Walker. With a background in product design and social innovation, she has been involved in several design projects and funded research projects both in China and UK. Her current thesis centres on design interventions in heritage making practices in the Chinese context. Her research interests include culturally significant designs and products, design for sustainability and craft-design collaborations.

ORCiD: https://orcid.org/0000-0002-2381-3798

Stuart Walker is Principal Investigator for the Located Making project. He is Professor of Design for Sustainability at Lancaster University, UK and Co-director of the ImaginationLancaster Design Research Centre. He is also Visiting Professor of Sustainable Design at Kingston University, London and Emeritus Professor at University of Calgary. His books include: Sustainable by Design, The Spirit of Design, The Handbook of Design for Sustainability (ed. with Jacques Giard) and Designing Sustainability. His recent books include Design for Life (2017), Design Roots (eds Walker, Evans, Cassidy, et al. 2018) and Design Realities (2018). His latest book Design and Spirituality was published in 2021 by Routledge, London.

ORCiD: https://orcid.org/0000-0002-0667-6373

Martyn Evans is Co-Investigator for this project. He is Professor of Design and Director of Manchester School of Art at Manchester Metropolitan University, Manchester, UK. As a trained product designer, his research interests explore the strategic approaches designers use to consider the future, in particular the ability of designers to envision potential social, cultural, technological and economic futures as a driver for innovation. He has led a number of major funded research projects, both in the United Kingdom and Europe. In 2019, he became a member of the Arts and Humanities Research Council's Advisory Board.

ORCiD: https://orcid.org/0000-0002-4002-8898

Julia Bennett is Head of Research and Policy at the Crafts Council. She develops policy and advocacy strategy, writes about craft and manages research, strengthening evidence to improve the conditions for craft. Research commissions include The Market for Craft, Studying Craft 16, an analysis of craft education and training, Innovation through Crafts: opportunities for growth and Measuring the Craft Economy. This resulted in the Department for Digital, Culture, Media \& Sport including data on the craft sector for the first time in its economic estimates. She has worked independently with small arts organisations, as well as for the Local Government Association, the Learning and Skills Improvement Service and the Minority Rights Group.

Funding We would like to thanks the Arts and Humanities Research Council - Newton Fund and the Ningxia University for providing financial support for this international collaborative project.

Availability of data and materials Not Applicable.

\section{Declarations}

Ethics approval and consent to participate Institutional Ethics Approval for this research was attained by the Faculty Ethics Committee, Lancaster University. All required consents were attained during 
interviews via the Project Information Sheet and Informed Consent Form, which are components of this ethically approved research.

Consent for publication Not Applicable.

Competing interests The authors declare that they have no competing interests.

Open Access This article is licensed under a Creative Commons Attribution 4.0 International License, which permits use, sharing, adaptation, distribution and reproduction in any medium or format, as long as you give appropriate credit to the original author(s) and the source, provide a link to the Creative Commons licence, and indicate if changes were made. The images or other third party material in this article are included in the article's Creative Commons licence, unless indicated otherwise in a credit line to the material. If material is not included in the article's Creative Commons licence and your intended use is not permitted by statutory regulation or exceeds the permitted use, you will need to obtain permission directly from the copyright holder. To view a copy of this licence, visit http:// creativecommons.org/licenses/by/4.0/.

\section{References}

Beijing Tourism. 2018. China releases list of the inheritors of National Intangible Cultural Heritage. http:// english.visitbeijing.com.cn/a1/a-XDHUQW73F1416817F11DA6. Accessed 22 June 2020.

Bennett, Julia. 2019. Crafts policies in the UK. In A cultural economic analysis of craft, ed. Anna Mignosa and Priyatej Kotipalli, 143-154. London: Palgrave Macmillan. https://doi.org/10.1007/978-3-030-021 64-1_12.

Bissett-Johnson, Katherine, and David Moorhead. 2019. Co-creating craft; Australian designers meet artisans in India. Textile Society of America Symposium Proceedings 1073. https://doi.org/10.32873/unl.dc.tsasp. 0004.

Braun, Virginia, and Victoria Clarke. 2012. Thematic analysis. In APA handbook of research methods in psychology. Vol. 2. Research designs: Quantitative, qualitative, neuropsychological, and biological, ed. Harris Cooper et. al., 57-71. Washington, DC: American Psychological Association, DOI: https://doi. org/10.1037/13620-004.

Burns, Robert. 2000. Introduction to research methods. London: SAGE publications.

Böhm, Andreas. 2004. Theoretical coding: Text analysis in grounded theory. In A Companion to Qualitative Research, 1st ed. Uwe Flick, Ernst von Kardoff and Ines Steinke, 270-275. London: SAGE Publications.

Cartwright, Mark. 2018. Yin and Yang. Ancient History Encyclopedia. https://www.ancient.eu/Yin_and_Yang/. Accessed 24 June 2020.

China Daily. 2010. History of Henan. https://www.chinadaily.com.cn/regional/2010-05/18/content_9863754.htm. Accessed 26 June 2020.

China Daily. 2017. Secure A Decisive Victory in Building a Moderately Prosperous Society in All Respects and Strive for The Great Success of Socialism with Chinese Characteristics for a New Era. http://www. chinadaily.com.cn/interface/flipboard/1142846/2017-11-06/cd_34188086.html. Accessed 26 June 2020.

Chudasri, Disaya, Stuart Walker, and Martyn Evans. 2020. Potential areas for design and its implementation to enable the future viability of weaving practices in northern Thailand. International Journal of Design 14 (1): 95-111. http://www.ijdesign.org/index.php/IJDesign/article/view/3128/895. Accessed 23 June 2020.

CTD Henan (Culture and Tourism Department of Henan Province). 2020. ICH list and ICH Inheritors list at national and provincial levels. [In Chinese.] https://hct.henan.gov.cn/2020/03-31/1311333.html. Accessed 27 May 2020.

Dagnino, Francesca Maria, Francesca Pozzi, Erdal Yilmaz, Nikos Grammalidis, Kosmas Dimitropoulos, and Filareti Tsalakanidou. 2015. Designing Serious Games for ICH Education. 2015 Digital Heritage. 2: 615-618. https://doi.org/10.1109/digitalheritage.2015.7419581.

Department for Digital, Culture, Media \& Sport. 1998. Creative industries mapping documents 1998. London: DCMS.

Flick, Uwe. 2014. An introduction to qualitative research. 5th ed. London: SAGE publications.

Gao, Bingzhong, Juwen Zhang, and Bill Long. 2017. The social movement of safeguarding intangible cultural heritage and the end of cultural revolutions in China. Western Folklore 76 (2): 167-180. https:// www.jstor.org/stable/44790970. Accessed 26 June 2020. 
Gateway to Research 2020. Located making: Unlocking the potential of cultural heritage by design. Gateway to Research. https://gtr.ukri.org/projects?ref=AH\%2FS00341X\%2F1. Accessed 23 May 2020.

Härkönen, Elina, Maria Huhmarniemi, and Timo Jokela. 2018. Crafting sustainability: Handcraft in contemporary art and cultural sustainability in the Finnish Lapland. Sustainability 10 (6): 1907. https://doi.org/1 $0.3390 /$ su10061907.

Holroyd, Twigger, Tom Cassidy Amy, Martyn Evans, and Stuart Walker. 2017. Wrestling with tradition: Revitalizing the Orkney chair and other culturally significant crafts. Design and Culture 9 (3): 283-299. https://doi.org/10.1080/17547075.2017.1370310.

Huang, Weibo, Handun Xiang, and Shaohui Li. 2019. The application of augmented reality and Unity 3D in interaction with intangible cultural heritage. Evolutionary Intelligence. https://doi.org/10.1007/s12065-019-00314-6.

ICH China. 2020a. China's National List of the representative intangible cultural heritage. [in Chinese.] http://www.ihchina.cn/project\#target1. Accessed 22 June 2020.

ICH China. 2020b. China's National List of the representative ICH inheritors. [in Chinese.] ICH China. http://www.ihchina.cn/representative\#target1. Accessed 23 June 2020.

Kuah, Khun Eng, and Zhaohui Liu. 2016. Intangible Cultural Heritage in Contemporary China and Hong Kong: An Introductory Overview. In Intangible Cultural Heritage in Contemporary China, ed. Khun Eng Kuah and Zhaohui Liu, 13-22. London: Routledge.

Lu, Zhicong, Michelle Annett, Mingming Fan, and Daniel Wigdor. 2019. 'I feel it is my responsibility to stream': Streaming and engaging with intangible cultural heritage through Livestreaming. In CHI conference on human factors in computing systems proceedings (CHI 2019), 1-14. New York: ACM.

Maags, Christina. 2018. Creating a race to the top. In Chinese heritage in the making, ed. Marina Svensson and Christina Maags, 121-144. Amsterdam: Amsterdam University Press.

Maags, Christina. 2019. Struggles of recognition: Adverse effects of China's living human treasures program. International Journal of Heritage Studies 25 (8): 780-795. https://doi.org/10.1080/13527258.2018.1542330.

Mamidipudi, Annapurna. 2018. Constructing common knowledge: Design practice for social change in craft livelihoods in India. Design Issues 34 (4): 37-50. https://doi.org/10.1162/desi_a_00510.

MCT (Ministry of Culture and Tourism). 2019a. The Introduction of the ICH Department. [In Chinese.] https://www.mct.gov.cn/gywhb/jgsz/bjg_jgsz/201809/t20180911_834746.htm. Accessed 23 May 2020.

MCT (Ministry of Culture and Tourism). 2019b. Methods on the Recognition and Management of Representative ICH Inheritors. [In Chinese.] http://www.gov.cn/zhengce/zhengceku/2019-12/25/content_5463959. htm. Accessed 23 March 2020.

Murray, Kevin. 2012. Outsourcing the hand: An analysis of craft-design collaborations across the global divide. Craft + Design Enquiry, no. 02. https://doi.org/10.22459/cde.02.2010.04.

Xinhua Net. 2019. China Focus: The Yellow River, Mother River of Chinese Nation. http://www.xinhuanet. com/english/2019-09/20/c_138408423.htm. Accessed 23 June 2020.

Neuman, William Lawrence. 2007. Basics of social research. 2nd ed. Boston: Pearson Education.

Niedderer, Kristina, and Katherine Townsend. 2014. Designing craft research: Joining emotion and knowledge. The Design Journal 17 (4): 624-647. https://doi.org/10.2752/175630614x14056185480221.

Noy, Chaim. 2008. Sampling knowledge: The hermeneutics of snowball sampling in qualitative research. International Journal of Social Research Methodology 11 (4): 327-344. https://doi.org/10.1080/13645570701401305.

Sanders, Elizabeth B.-N., and Pieter Jan Stappers. 2008. Co-creation and the new landscapes of design. Codesign 4 (1): 5-18. https://doi.org/10.1080/15710880701875068.

Schwartz, Shalom H. 2012. An overview of the Schwartz theory of basic values. Online Readings in Psychology and Culture 2 (1). https://doi.org/10.9707/2307-0919.1116.

$\mathrm{Su}$, Xinwei, Xi Li, Yanbin Wu, and Limei Yao. 2020. How is intangible cultural heritage valued in the eyes of inheritors? Scale development and validation. Journal of Hospitality \& Tourism Research 44 (5): 806-834. https://doi.org/10.1177/1096348020914691.

Tung, Fang-Wu. 2012. Weaving with rush: Exploring craft-design collaborations in revitalizing a local craft. International Journal of Design 6 (3): 71-84. http://www.ijdesign.org/index.php/IJDesign/article/view/1077.

UNESCO. 2001. UNESCO Universal Declaration on Cultural Diversity. http://portal.unesco.org/en/ev.phpURL_ID=13179\&URL_DO=DO_TOPIC\&URL_SECTION=201.html. Accessed 23 Mar 2020.

UNESCO. 2018. Basic Texts of the 2003 Convention for the Safeguarding of the Intangible Cultural Heritage. https:// ich.unesco.org/doc/src/2003_Convention_Basic_Texts-_2018_version-EN.pdf. Accessed 23 Mar 2020.

UNESCO. 2020a. China's Properties Inscribed on the World Heritage List. http://whc.unesco.org/en/statesparties/CN. Accessed 23 Mar 2020.

UNESCO. 2020b. Traditional Craftsmanship. https://ich.unesco.org/en/traditional-craftsmanship-00057. Accessed 23 Mar 2020. 
Väänänen, Niina, and Sinikka Pöllänen. 2020. Conceptualizing sustainable craft: Concept analysis of literature. The Design Journal 23 (2): 263-285. https://doi.org/10.1080/14606925.2020.1718276.

Vencatachellum, Indrasen. 2019. UNESCO approach to crafts. In A cultural economic analysis of crafts, ed. Anna Mignosa and Priyatej Kotipalli, 25-37. London: Palgrave Macmillan. https://doi.org/10.1007/ 978-3-030-02164-1_3.

Walker, Stuart, and Martyn Evans. 2018. Design futures - editorial introduction. In Design roots: Cultural significant designs, products and practices, ed. Stuart Walker, Martyn Evans, Tom Cassidy, Jeyon Jung, and Amy Twigger Holroyd, 273-275. London: Bloomsbury Academic. https://doi.org/10.5040/97814 74241823.ch-025.

Walker, Stuart, Martyn Evans, and Louise Mullagh. 2019a. Meaningful practices: The contemporary relevance of traditional making for sustainable material futures. Craft Research 10 (2): 183-210. https://doi. org/10.1386/crre_00002_1.

Walker, Stuart, Louise Mullagh, Martyn Evans, and Yanzhong Wang. 2019b. Design ecologies: Sustaining ethno-cultural significance of products through urban ecologies of creative practice. International Journal of Anthropology and Ethnology 3 (1). https://doi.org/10.1186/s41257-019-0025-7.

Wood, Nicola, Chris Rust, and Grace Horne. 2009. A tacit understanding: The Designer's role in capturing and passing on the skilled knowledge of master craftsmen. International Journal of Design 3 (3): 65-78 http://www.ijdesign.org/index.php/IJDesign/article/view/559/275.

$\mathrm{Wu}$, Baosan. 2014. On the major fields and significance of the study of the history of ancient Chinese economic thought. In The history of ancient Chinese economic thought, ed. Chen Lin, Terry Peach, and Fang Wang, 46-65. London: Routledge.

Yang, Haicui. 2018. Study on the cultural self-confidence of socialism with Chinese characteristics. Open Journal of Social Sciences 06 (08): 235-239. https://doi.org/10.4236/jss.2018.68019.

Zhan, Xiaofang, and Stuart Walker. 2018. Value direction: Moving crafts toward sustainability in the Yangtze River Delta, China. Sustainability 10 (4): 1252-1272. https://doi.org/10.3390/su10041252.

Zhang, Juwen. 2017. Intangible cultural heritage and self-healing mechanism in Chinese culture. Western Folklore 76 (2): 197-226. https://www.jstor.org/stable/44790972.

Zhou, Guiying. 2012. On ups and downs of Chinese cultural confidence. Asian Culture and History 4 (2). https://doi.org/10.5539/ach.v4n2p140.

\section{Comments}

Publisher's Note Springer Nature remains neutral with regard to jurisdictional claims in published maps and institutional affiliations. 